\title{
Development of a prototype with wireless sensors for detection of forest fires
}

\author{
Ronie Silva Juvanhol ${ }^{1}$, Amanda Cavalcante da Silva ${ }^{l}$
}

${ }^{1}$ Universidade Federal do Piauí, Teresina, Brasil
*e-mail: roniejuvanhol@gmail.com

ABSTRACT - Each year, in several countries of the world, large expanses of forest are lost due to the fires, causing impacts social and economic. A strategy designed to lessen or even prevent the occurrence of forest fires is the implementation of detection and prevention systems in forest areas. In this sense, as for the detection systems, can be highlighted more traditional media, like conventional observation towers and ground patrol; or even, through monitoring of automatic cameras installed in the towers, satellite monitoring, air patrol and more recently, in some countries, wireless sensor networks, distributed in the area to be monitored. Studies show that there are advantages and disadvantages in many different means of detection, since your operating cost, efficiency and your coverage area. In this context, the present work aims to develop and evaluate the performance of a system of wireless sensors, adaptable and that integrates the different devices and technologies, with the aim of detecting forest fires. For the development of the prototype are being considered the sensors of smoke, relative air humidity and temperature. The prototype developed as a product of this project will have direct connection to cell phones, tablets or laptops, through the submission of data to a cloud, through the shield device to ethernet connected to an Arduino board. The wireless sensor system will be programmed to send beeps alert when a fire is detected, allowing a real-time experience, with access to the data collected by the sensors. With the validation tests of the prototype in an area considered at risk, in the Serra das Confusões National Park, located in the State of Piauí in the Northeast region of Brazil, is expected to validate the efficiency of prototype for detection of forest fires, as well as a better combat management on the part of managers and actuators in the operation. The importance of this project is evidenced by the technological innovation in the field of forest protection and the possibility of new alternatives of control systems that are viable economically.

Keywords: forest protection, Arduino, technological innovation 